\title{
Increasing the Pace of an Integral Library System in China: Moving toward the Twenty-First Century
}

\section{Qiang Zhu (translated by Sha Li Zhang)}

\begin{abstract}
Academic libraries in China are transforming traditionally isolated and separated operations by initiating an integral library system (also known as integral system development) to connect all academic libraries nationwide, and to connect them with other information networks abroad. A three-tier network at the national, regional, and campus levels should be developed. This paper describes the current academic library environment in China, the concept of the integral library system, and the major goals to be realized in the next five years.
\end{abstract}

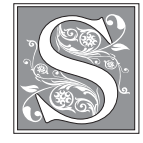

ince 1979, when economic reform policies were implemented in China, academic libraries have experienced rapid changes. These changes indicate that academic libraries no longer can operate in a historically isolated environment. Academic libraries in China have to actively employ new information technologies, initiate an integral library system, establish networked information systems, and connect with other networked information systems, both at home and abroad. A nationwide information resources-sharing system in China can only be realized if most of the libraries participate, cooperate, and share resources. In recent years, China's academic libraries have explored advanced technologies from other countries in order to develop state-of-the-art academic library information systems. These advanced systems will enable China's academic libraries to move suc- cessfully into the new millennium and meet the challenges offered by the globalization of information.

\section{Current Academic Library Environment}

Like many other libraries of developing countries, academic libraries in China are now at a crossroads. Lack of funds to support library collections and lack of technological capabilities are serious problems; these issues prevent the academic library community from offering basic services and from participating in the sharing of information resources.

In the past ten years, the costs of foreign monographs and journals (published outside China) increased 15 to 25 percent while Chinese monographs and journals increased 20 to 30 percent. These increases have had a severe impact on the academic library community. In a survey conducted by the National Academic Li- 
braries Commission of China between 1986 and 1991, materials' budgets increased 43.21 percent, but the total volumes purchased fell 67.04 percent. Tsinghua University Library, for example, purchased 30,000 volumes of foreign monographs in 1986. In 1991, only 5,210 volumes of foreign monographs were added to the library's collections. ${ }^{1}$ Some university libraries had to stop purchasing foreign materials for several years due to their high cost. In 1995, Peking University Library purchased 4,000 volumes of foreign monographs, and only 1,000 of them came from the materials budget allocated by the university; the remainder was purchased by special funds. ${ }^{2}$

\section{Some university libraries had to stop purchasing foreign materials for several years due to their high cost.}

Many university libraries use a large portion of their materials budget to retain journal subscriptions. Among major university medical libraries, 80 to 90 percent of the materials budgets are used for journal subscriptions. Major science and engineering libraries allocate up to 70 percent of their materials budget for journal subscriptions. In 1995, Peking University Library used 3.5 million yuan (equivalent to $\$ 440,000$ U.S. currency) of its 4 million yuan (equivalent to $\$ 500,000$ U.S. currency) materials budget for journals. In the same year, among seventyone major university libraries in China, there were only subscriptions to 6,000 foreign journal titles. It is estimated that 150,000 journals and 600,000 monographs are published annually around the world. If one-third of them are scholarly titles, the academic libraries in China annually collect less than 20 percent of foreign journals and less than 10 percent of foreign monographs. ${ }^{3}$

Some efforts have been made in acquisitions coordination among China's academic libraries. However, due to shrinking budgets and the current administrative practices within each university, it is very difficult to initiate any cooperative projects to wisely distribute information resources on a nationwide scale. Each library makes decisions based on its own immediate needs (e.g., reassigning monograph funds for journal subscriptions and canceling less-used journals to retain core journal titles). Among these core titles, the expensive journals are often the candidates for further cancellations. As a result, some important foreign journals are not acquired by any university libraries. These libraries collect the same inexpensive journal titles. Duplication and gaps in collections exacerbated the shortage of information resources among academic libraries.

Lack of technological capabilities presents another barrier. In more than 1,000 academic libraries in China, less than 5 percent of them are using computers for library functions. Peking University Library and Tsinghua University Library are the only two academic libraries in the country that are able to access their online catalogs through the Internet. ${ }^{4}$ Most libraries still use manual systems for acquisitions, cataloging, processing, searching, and circulation. Thus, it is impossible for one library to know the holdings in other libraries' collections.

In recent years, some university administrations have allocated funds for purchasing computer equipment for their libraries, but they did not allocate funds at the same time for purchasing the necessary software and databases. Therefore, the computer hardware is not being fully utilized.

There has been very little cooperative planning among China's academic libraries. They started their respective automation projects independent of one another. A few years ago, the Technology and Equipment Department of the State Education Commission sponsored a project for retrospective conversion of Chinese bibliographical union catalogs. 
It was a successful project at the beginning. Unfortunately, the lack of continued funding from the commission prevented the project from further development.

Lack of adequate information resources and technologies has widened the gap between the academic libraries in China and their counterparts in other countries. The practices and experiences from developed countries have proved that isolated and separate/independent library operations are not the appropriate paths to pursue. A new model needs to be explored and designed to enable academic libraries in China to increase their access to information resources and to improve the quality of services. When these goals are realized, the academic libraries will be able to better serve their university communities, participate in sharing global information resources, and contribute to global networked information systems.

\section{Concept of the Integral Library System}

An integral library system is needed to enhance access to information resources and to improve services. By using computer networks to connect each academic library and to connect with information resource networks abroad, China can transform isolated and separated systems into a nationwide information resources-sharing system. In this environment, the Chinese Education and Research Network (CERNET) will serve as the backbone to support a networked system in the academic library community. Under the direction of the National Education Commission, long-range planning should be placed at the national level (first tier). Information resources should be purchased at the regional level (second tier) and accessed at the university campus level (third tier). Joint services and support should be coordinated to improve efficiency and quality of services. Additional funds should be provided for selective university libraries to expand their information resources and to acquire the newest technology and equipment. These selective library sites will become multidisciplinary information resources centers. It is reasonable to encourage the development of a nationwide and multitier information resourcessharing system. This system should be connected via telecommunications networks with major networked resourcessharing systems abroad in order to meet increasing demands from university communities.

\section{There has been very little coopera- tive planning among China's academic libraries.}

The concept of the integral library system can be traced back to the early 1980s. In September 1981, at the National Academic Libraries Working Conference held in Beijing, organized by the Department of Education (formerly the State Education Commission), Lin Zhou, deputy director of the department at that time, stated in his report that academic libraries "must be actively engaged in cooperation and in sharing resources." 5

One year later, at the Second Plenary Session of the National Academic Libraries Working Commission meeting, the concept of the integral library system was presented more clearly. It was agreed that to move each library from its isolated and separated environment into an integral system was one of the best ways to improve library services. Therefore, the integral library system should have:

- nationwide planning;

- uniform standards and protocols;

- a group of libraries serving as cores and backbones for new initiatives and endeavors;

- an environment encouraging coordination and cooperation among libraries;

- a group of libraries that shares modern facilities/service centers. ${ }^{6}$ 
In June 1987, a document from the State Education Commission addressed the need to establish a group of disciplinary information resources centers and to form an information resourcessharing system within the academic library community. In this document, preliminary plans addressing the responsibilities of disciplinary information centers, required facilities, the number of centers, funding for these centers, and management of these centers also were presented. ${ }^{7}$ However, due to many reasons at that time, these discussions did not form any concrete plan of action. Some important lessons from this group included that the scale of the assumption for the integral library system was too broad. The guiding principles emphasized developing information resources but did not address how to provide access to university communities. In addition, no consideration was given to networks and the various

\section{The guiding principles emphasized developing information resources but did not address how to provide access to university communities.}

types of systems. At any rate, the discussions generated from the document provided the basic principles for the integral library system. Based on these principles, the National Academic Libraries Working Commission conducted a large-scale survey of information resources. It also started the coordination of acquisitions for foreign journal subscriptions. The State Education Commission funded information resources centers for humanities and social sciences at fifteen university campuses. Later, it funded foreign monographs centers for humanities and social sciences at five university campuses. ${ }^{8}$ These activities enabled university libraries to share vital information resources and to gain useful experience for the integral library system.

Project 211 provides an excellent opportunity for the integral library system. The project, sponsored by the State Education Commission, is the Chinese government's new endeavor for enhancing one hundred universities and key subject disciplinary areas as a national priority for the twenty-first century. According to this plan, in the next five years the government will initiate actions to strengthen a hundred universities and key disciplinary areas. It is envisioned that after the implementation of Project 211, the one hundred universities and key disciplinary areas will have greatly improved their quality of education, scientific research, management, and institutional efficiency. ${ }^{9}$ This project consists of three major components: (1) improvement of overall institutional capacity, (2) development of key disciplinary areas, and (3) development of the public services system of higher education. The third component includes three subsets: (1) development of CERNET, (2) development of the China Academic Library and Information System (CALIS), and (3) development of the Modern Equipment and Facilities Sharing System (MEFSS). CERNET will link all major universities in China via the Internet and will provide information services to people in all of China's sectors. ${ }^{10}$

\section{Goals of the Integral Library System}

From now to the year 2000 and beyond, the major goals of the integral library system include development of CALIS to its fullest operation. Backed by CERNET, CALIS will establish numerous comprehensive information resources centers and disciplinary information resources centers, thus forming an information subnetwork with extensive connections to similar systems both at home and abroad. Funded by the State Education Commission, 80 
percent of CALIS's budget will be used for purchasing information resources and databases, leasing databases from abroad, paying for connection fees with other online databases abroad, and paying for international document delivery. Ten percent of the budget will be used for developing databases and training professional staff; the remaining 10 percent will be allocated for planning, research, maintenance, etc.

Goals for the integral library system include:

1. Establishing a services backbone network with centralized information resources at the national and regional centers, including access channels by the university libraries. Because of the unique situation of academic libraries in China, it is practical that CALIS should employ a structural model for establishing information resources centers at national and regional levels. Through regional centers, each academic library can therefore be connected to form a three-tier support services network.

One of the first steps is to establish a nationwide information resources centers for such disciplinary areas as liberal arts, engineering and technologies, medicines, agriculture, and forestry. Numerous regional information resources centers should be established accordingly in the cities where major colleges and universities are located, rich information resources can be provided, a practice of sharing resources is in existence, and the use of advanced networks is present. Within these centers, there should be adequate information resources and competent professionals, including a certain number of knowledgeable workers and experts who engage in the processing and searching of information resources. They should have access to advanced facilities (i.e., computer equipment, networks, telecommunications facilities, and document-duplicating equipment). These centers will provide information resources sharing, coordination, and services nationwide and at the regional levels. Their activities should include coordinating acquisitions, increasing collections of original documents, and organizing and promoting the existing resources. It is very important that there be effective communication with the National Library of China, Science Academy Libraries, special libraries, and public libraries.

During this period of time, at least a hundred university libraries should be connected with the national backbone network (CERNET). These libraries will participate in the development of centralized information resources and the contribution of local resources according to the system's standards. These participating libraries also will be entitled to privileges and services provided by the system.

2. Developing bibliographical databases and documentation databases. Academic libraries in China hold a large amount of information resources. The resources increase in number steadily each year. To maximize the use of these resources, there is the need to develop comprehensive bibliographic and documentation databases. Thus, the scattered collections in each library will be known by participating libraries within the network.

In addition, there is a growing number of vital information resources produced abroad. With the development of networks, the use of electronic resources has expanded significantly. To utilize these resources effectively, there is an urgent need to develop databases at home, to purchase databases from abroad, and to have the proper protocols in place to access information from the developed countries.

The development and use of databases includes two steps: (1) to design and build databases at home, and (2) to purchase and/or access databases from abroad. The first step includes developing union catalog databases for monographic and periodical collections in the Chinese language and foreign languages. The second step involves developing documentation 
databases from collections owned by individual libraries. In addition, there is the need to develop subject-oriented databases to support academic programs and research. To avoid duplicate efforts, a coordinated purchasing policy must be formulated that stipulates specific criteria. With collective efforts, the databases should have comprehensive coverage in appropriate disciplinary areas.

Regarding the purchase of databases from abroad, every effort needs to be made to eliminate unnecessary duplication and to avoid internal competition. The types of databases should have a balance in formats of abstracts, indexes, full text, and access to original documentation. Because academic libraries are spread over a wide geographic area in China, there are no networks and telecommunication facilities in existence in some geographical locations.

3. Conducting research on key technologies and projects. Development of CALIS includes not only telecommunications, computer equipment, and other technical aspects of library automation but also information processing, organizational aspects, access issues, and basic services. There are some existing solutions for the problems pertinent to these aspects. For the unsolved problems, applied research on key technologies and pertinent projects should be conducted. There also is the need to follow the tracks of research pertaining to advanced technologies for the future.

Because the information resourcessharing system is of a large scale and spread over a huge geographic area, the following projects are targeted for research and development:

- production and access systems for distributed databases;

- manufacturing and access systems for multimedia databases;

- designing, organizing, and accessing of union catalog databases;

- collecting, organizing, and accessing networked electronic resources;
- interlibrary loans and document delivery;

- equitable distribution of information resources and coordination of acquisitions;

- evaluation criteria and research methods for core documentation in key disciplinary areas;

- information resources sharing and protection of intellectual property;

- assessment and research on new information technology products abroad;

- digital library technologies.

In conducting research for these technologies and projects, cooperation and coordination should be promoted. Exchanges with experts both at home and abroad should be encouraged to ensure the currency of technologies.

4. Training human resources for new systems/services. Human resources are a key component of CALIS. There should be a large number of knowledgeable workers who understand modern information technologies. Human resources include systems research and development personnel, systems operation and maintenance personnel, database development personnel, user education personnel, and user services personnel. University libraries should make commitments to invest resources to recruit college graduates and overseas students to work in these areas. However, the practical way at present is to train the existing library staff members in each academic library and to improve and upgrade their knowledge and skills. Every effort needs to be made to improve human resources, for example, to:

- establish several training bases nationwide to enable library staff to obtain professional knowledge and skills. The trained staff should be certified upon completion of training.

- set up policy and procedures to encourage library staff to enroll for degrees and course work. 
- send library staff members overseas to observe and study current technologies and practices.

- invite experts and scholars from abroad to engage in exchanges.

- hold conferences for scholarly and technical discussions.

5. Establish a management structure that ensures systems operations. In the process of developing CALIS, there is the need to establish scientific management and related policies and procedures; they would be emphasized in the following ways:

- Throughout the organizational structure, priority should be given to highly efficient management. Also, there should be a scholarly advisory board and a democratic supervising group.

- The entire system and subsystems should be task oriented and should enhance continual assessment/ evaluation to ensure the completion of each project.

- There should be a series of regulations and policies to ensure that all projects follow appropriate guidelines.

- Priority has to be given to the improvement of services in order to meet users' demands.

Upon its completion, CALIS will provide the following services to enable university communities and other users to:

- search library holdings through online monographic and periodical union catalogs;

- search journal articles and other documents through various databases both at home and abroad;

- obtain journal articles and other types of documents through document delivery and interlibrary loan services;

- search updated research proposals to avoid duplicate efforts in research projects;

- coordinate acquisitions for monographs and journals to maximize use of the materials budget and to distribute information resources wisely;
- catalog library materials through online union cataloging databases according to uniform standards to enhance the sharing of information resources.

Along with development of CALIS and use of emerging technologies, new functions and new services will be added to the list above. However, the demands for expertise and for funding in the development of CALIS are as high as that of CERNET.

\section{Conclusion}

The new millennium is quickly approaching. The twenty-first century will be the era of information. In the intensive international competition, information resources play a vital role in the development of the economy, sciences, and technologies. Improving the human condition via science and education in China cannot be realized unless information resources are expanded/networked and services are improved.

\section{Improving the human condition via science and education in China cannot be realized unless information resources are expanded/networked and services are improved.}

The development of CALIS, whose purpose is to connect university libraries with CERNET, allows the development of information resources networks through extensive use of modern technologies. The implementation of CALIS will ensure moving higher education and scientific research capability to a higher level. At the same time, as an integral part of a nationwide information resources network, CALIS will contribute to the social and economic development of the country by bringing the accomplishments of science, technologies, and cultures of China to the world's attention.

In the next five years, the principles for CALIS development include taking vigorous, but steady steps in establishing appropriate goals and priorities to 
achieve maximum results. Every positive factor needs to be brought into play to complete what has been planned with an orderly manner. Therefore, the following will be realized:

1. Fully organize and develop the existing collections to realize the sharing of information resources. Although Chinese language materials will be collected by each individual library, interdisciplinary Chinese language materials will be developed at the regional centers. These centers will be cooperative and interdependent. It is critical to follow a coordinated approach in order to prevent duplication in expensive journal subscriptions. Steady progress is expected in the development of a series of databases that reflect the unique characteristics of China's academic library community. Some databases will be purchased from developed countries to supplement printed materials. Therefore, the development of information resources for institutions of higher education will leap to a new stage.

2. Develop a three-tier services network at the national, regional, and campus levels to connect with information resources networks abroad. These connections are expected to improve academic library ser- vices significantly. Selected universities will be encouraged to equip their libraries with modern telecommunications / computer technologies. These libraries will become modernized information resources centers.

3. Train library staff to become more proficient in the use of modern technology. They will develop standards, protocols, policies, and procedures. Also, organizational structures will be put into place that ensure the successful operation of the system. These implementations will form a model of the integral library system.

China's integral library system is expected to dramatically improve academic library services. It will serve as the foundation on which to build future planning, growth, development, and innovation. This cooperative and systematic approach in sharing vital information resources among China's academic libraries is expected to result in many benefits for users.

The Chinese version of this article appeared in the Journal of Academic Libraries 15, no. 2 (1997): 6-9. This article is the first of the exchange of articles between C\&RL and the Chinese Journal of Academic Libraries.

\section{Notes}

1. Xiao-ming Li, "Development of Information Resources for Academic Libraries: Current Situation and Recommendations," Journal of Academic Libraries 11, no. 5 (1993): 1-3.

2. Qiang Zhu, "Issues on the Development of China Academic Library and Information System," Journal of Academic Libraries 14, no. 1 (1996): 1-6.

3. Ibid., 1.

4. Ibid., 2.

5. Lin Zhou, "Reaching Consensus and Providing Leadership: Toward a Better Academic Library," in Proceedings of the National Academic Library Working Conference (Beijing, China: The National Academic Library Working Commission, 1981), 11-24.

6. Shou-jing Zhuang, "Inspire Enthusiasm for a New Phase of Academic Libraries," Journal of Academic Libraries 1, no. 1-2 (1983): 19.

7. The Secretariat of the National Academic Library Working Commission, "Key Issues of Academic Libraries during the 7th Five-Year Plan," Journal of Academic Libraries 5, no. 5 (1987): $24-26$

8. URL:http://www.lib.pku.edu.cn/chtml/hsf/e-jih.htm.

9. Department of Foreign Affairs of the State Education Commission, Project 211: A Brief Introduction (Beijing, China: Department of Foreign Affairs of the State Education Commission, 1996), 1.

10. Ibid., 4. 